\title{
A metrópole entre o neoliberalismo e o comum: disputas e alternativas na produção contemporânea do espaço
}

\author{
The metropolis in-between neoliberalism \\ and the common: disputes and alternatives \\ in the contemporary production of space
}

João Bosco Moura Tonucci Filho Felipe Nunes Coelho Magalhães

\begin{abstract}
Resumo
Oposto às racionalidades neoliberais que tendem a estender os imperativos do mercado e da propriedade privada a todas as esferas da vida, o comum delineia a construção de formas cooperativas de produção e gestão de recursos compartilhados. Propomos, neste artigo, uma breve reflexão teórica acerca de como as contradições da produção do espaço da metrópole contemporânea podem ser compreendidas a partir do embate entre esses dois polos políticos contrapostos - 0 neoliberalismo e o comum. Para tanto, exploramos injunções e cruzamentos geo-históricos entre neoliberalismo e metrópole, assim como processos de endividamento e financeirização da cidade. Apresentamos as principais formulações críticas do comum e apontamos para a crescente relevância do comum urbano como alternativa à metrópole do neoliberalismo.
\end{abstract}

Palavras-chave: metrópole; neoliberalismo; financeirização; o comum; comum urbano.

\begin{abstract}
In opposition to neoliberal rationalities that tend to extend the imperatives of the market and of private property to all spheres of life, the common delineates the construction of cooperative forms of production and management of shared resources. In this article, we propose a brief theoretical reflection on how certain contradictions in the production of space in the contemporary metropolis can be understood through the clash between these two opposing political poles - neoliberalism and the common. The paper explores geo-historical injunctions and interlacements between neoliberalism and the metropolis, as well as the processes of indebtedness and financialization of the city. We present the main critical theoretical formulations concerning the common and highlight the growing relevance of the urban commons as an alternative to the neoliberal metropolis.
\end{abstract}

Keywords: metropolis; neoliberalism; financialization; the common; urban commons. 


\section{Introdução}

A metrópole contemporânea, em larga medida resultado geo-histórico de um processo amplo de industrialização e modernização econômica, é marcada pela densidade crescente de relações transescalares que conectam dinâmicas urbanas localizadas a processos e agentes distantes. Ao longo da dinâmica sócio-histórica de formação desse ente geográfico, adensaram-se relações que interligam a cidade - que se torna metrópole através da industrialização - ao terreno, situado e operado na escala do Estado-nação, da macroeconomia e da política econômica. Mesmo após o declínio de um regime de acumulação centrado na indústria, esse vínculo permanece em cena de forma decisiva na dinâmica metropolitana contemporânea.

Para além dessa primeira forma com que as transformações sociais operadas pelo neoliberalismo se fazem presentes na metrópole, há também um fortalecimento progressivo de formas de operação e realização do neoliberalismo a partir do Estado nas escalas local e regional - em grande medida a partir do imperativo das chamadas vantagens comparativas e de uma forma de planejamento e gestão em busca de uma suposta eficiência pautada pelos padrões do mercado, logo, abrindo terreno para sua expansão e predomínio. A produção do espaço atravessada por processos (governamentais) neoliberais envolve a ativa construção de um conjunto de pressupostos sociopolíticos para esse fortalecimento do mercado: contratos, propriedade, polícia, formação da oferta de mão de obra - através dos cercamentos, do bloqueio ao surgimento de alternativas autônomas de sobrevivência, do sufocamento do comum.
De modo geral, o comum refere-se as bens e recursos, materiais ou imateriais, que são compartilhados, usados e geridos coletivamente, por meio de uma série de práticas, regras e saberes gestados pela própria comunidade. Nos dias de hoje, as práticas e os conceitos do comum estão se fortalecendo em torno de um princípio político que suporta, ajuda a articular e reconhece a potência de uma pluralidade de lutas, resistências e alternativas radicais ao Estado e ao mercado. Opondo-se à propriedade privada, fundada no direito de excluir, o comum não se confunde com a propriedade pública do Estado, mais bem entendida como forma coletiva de propriedade privada.

Muitas das lutas que se opõem ao neoliberalismo são animadas e orientadas pelo comum, contra a crescente onda de cercamentos daquilo que é considerado patrimônio "comum" da humanidade (a natureza, o espaço público, as culturas, o conhecimento, etc.) e contra a extensão da lógica da mercadoria a todas as esferas da vida. A ideia política do comum reapareceu ainda com mais força no último ciclo global de protestos (Primavera Árabe, movimentos das praças, occupy, etc.) detonado pela crise do capitalismo em sua face financeira e neoliberal, sustentando e orientando a construção de múltiplas experiências que se pretendem autônomas, democráticas e autogeridas.

Em diferentes metrópoles ao redor do mundo - e não coincidentemente nos países mais impactados pela atual crise -, a ideia do comum urbano tem sido invocada por movimentos, manifestantes, coletivos, pesquisadores, ativistas e até por formuladores de política pública, para fazer referência a recursos e espaços urbanos compartilhados e para reivindicar 
mais amplamente que a cidade como um todo seja mais aberta ao uso, à apropriação coletiva e à participação. Ao apontar para modos mais cooperativos e compartilhados na produção contemporânea do espaço urbano, contra a hegemonia da competição e da propriedade privada, a metrópole do comum emerge como uma potente crítica e alternativa concreta à metrópole do neoliberalismo.

Portanto, propomos, neste artigo, uma breve reflexão teórica acerca desses dois polos políticos opostos - o neoliberalismo e o comum (como em Dardot e Laval, 2014) - tendo a metrópole contemporânea como sujeito atravessador, espaço produzido que é aglutinador de ambos, enquanto potência e/ou realidade vivida/sobrevivida. A primeira parte é dedicada à compreensão de injunções e cruzamentos geo-históricos entre neoliberalismo e metrópole, assim como dos processos de endividamento e financeirização da cidade. A segunda parte explora algumas formulações críticas do comum e aponta para a crescente relevância do comum urbano na metrópole contemporânea. Por fim, nas considerações finais, são levantadas algumas questões em aberto - teóricas e práticas - quanto aos enfrentamentos entre 0 neoliberalismo e o comum na metrópole.

\section{A metrópole do neoliberalismo}

\section{Camadas e linhagens de um cruzamento geo-histórico}

Dentre uma série de outras dinâmicas, o urbano é resultante da relação Estado-espaço com uma dinâmica econômica que Ihe dá movimento. Pensar no caso brasileiro envolve trazer à tona a herança e as genealogias coloniais dessa relação, considerando suas presenças e persistências em suas manifestações socioespaciais. A relação Estado-espaço sob o neoliberalismo necessariamente interage com 0 legado de tal percurso histórico, e essa interação é um aspecto fundamental na produção do espaço na metrópole hoje. Ou seja, abordar o processo de neoliberalização em contextos semiperiféricos específicos, como as experiências latino-americanas, invoca a necessidade de compreender a formação econômico-social e espacial resultante dos processos históricos anteriores sobre a qual essa dinâmica de aprofundamento do neoliberalismo atua e com a qual ela interage - bastante distinta das geografias resultantes da experiência fordista-keynesiana nos países de centro.

A escala da economia nacional e da política macroeconômica - tanto no sentido da ação governamental de curto prazo, voltada para dinâmicas inflacionárias, de crescimento, de câmbio, etc., quanto no que diz respeito às políticas de longo prazo, de desenvolvimento ou de reestruturação econômica na escala da nação - traça relações diretas com a metrópole. ${ }^{1}$ Para além disso, no caso brasileiro, as origens da própria transformação da cidade (administrativa, mercantil, portuária) em metrópole (industrial e sede de uma hiperconcentração de atividades de serviços avançados) são diretamente vinculadas a transformações de ordem macroeconômica e à própria gênese da macroeconomia - enquanto técnica aplicada à governamentalidade. 0 período entre 1930 e 1980 conforma no Brasil um arranjo espacial (Harvey, 1982), centrado na metrópole, adequado à centralidade da indústria no formato de acumulação de capitais vigente, 
em que havia a necessidade de uma ampla oferta de mão de obra de baixo custo, bem como a concentração de condições gerais de produção (Lojkine, 1981) adequadas à fluidez e à expansão da atividade industrial. A metrópole transforma a cidade numa máquina de crescimento econômico com efeitos na escala nacional, agregando elementos necessários para a acumulação centrada na indústria, eliminando - através do Estado - barreiras, gargalos ou ameaças políticas (que a própria cidade engendra, como um produto urbano, da densidade, da pólis). 0 modelo econômico centrado na metrópole que se cria a partir dessa guinada nacional-desenvolvimentista baseada na industrialização substitutiva de importações de 1930 passa por diversos ciclos de crises e reestruturação interna, mas é somente com a crise da dívida da década de 1980, que atinge as maiores economias latino-americanas de forma avassaladora, que o ponto de inflexão gerado pela crise é profundo o suficiente para ocasionar a desestruturação do próprio regime de acumulação. As consequências desse período de crise e tentativas de reestruturação para as metrópoles foram decisivas. 0 arranjo espacial metropolitano voltado para a expansão e a fluidez da acumulação industrial deixa de ser veículo, durante esse período, do crescimento econômico ao qual ele serviria progressivamente a partir da década de 1930. Nisso, convoca-se (muitas vezes à força) um grande contingente populacional a participar desse amplo processo, para abandoná-lo em seguida. Enquanto o crescimento assistido no período autoritário criou pobreza urbana, concentrou renda e produziu espaços espoliados, sua herança combinada à ausência do crescimento em si envolve consequências ainda mais nefastas. Este é o legado sobre o qual a reestruturação neoliberal posterior atuaria, e suas interfaces urbanas se agenciam também por sobre - e em meio a - essa paisagem sócio-histórica herdada.

A partir de sua constituição como um espaço de concentração de relações entre escalas, dentre elas a ligação direta entre globalização, macroeconomia e produção do espaço urbano, a metrópole torna-se agenciadora e mediadora transescalar do neoliberalismo, tornando esse formato de governo real na vida cotidiana, de forma próxima e imediata, "descendo" do plano da macroeconomia ao espaço da vida. 0 período de crise gerada pela reestruturação que atinge em cheio o Estado e a economia brasileiros na década de 1980 transforma a metrópole num ponto de grande concentração de eventos e processos derivados da crise. Em contraste com a onda que se fortalecia naquele momento através dos movimentos de reforma urbana na direção da democratização da política e do planejamento urbano, o neoliberalismo se apresenta, nesse contexto, como um prognóstico de saída da crise através da promoção das virtudes do mercado que seria progressivamente adotado no plano macroeconômico e em diversas cidades e regiões não alinhadas politicamente àquela dinâmica de busca por democratização do planejamento e da gestão na escala urbana.

0 imperativo da busca por vantagens comparativas como forma de saída da crise se faz presente de diversas formas e atinge as relações entre regiões e cidades, que passam ao plano da promoção da competição em diversos níveis de agentes (desde os indivíduos até os próprios Estados, sendo a exposição ao risco um princípio fundamental no estímulo ao ganho de competitividade). Como argumentam 
Peck e Tickell (2002), há um processo de neoliberalização do espaço em que as relações espaciais são tornadas neoliberais e em que as cidades e regiões se relacionam umas com as outras a partir de padrões de competição (inclusive entre modos de regulação mais eficientes e favoráveis ao crescimento e ao investimento privado). Nisto, cidades e regiões tornam-se agentes neoliberais fundamentais, pois a própria competição entre territórios torna-se um fator importante na dinâmica geoeconômica do neoliberalismo, passando a ser insumo de decisões de investimento e localização que rebatem sobre a própria dinâmica regional e nos próprios padrões de regulação praticados de forma decisiva.

Em relação à busca por vantagens comparativas como um princípio norteador e uma prática que tende a se tornar onipresente no neoliberalismo, a cidade regida a partir desse preceito opera predominantemente a partir do mercado - e, nesse processo, o solo urbano torna-se uma mercadoria primordial da cidade-empresa, agenciado pelo seu planejamento, com desdobramentos importantes na direção da financeirização do espaço urbano, como veremos adiante. A partir do momento em que a competição pelo solo metropolitano atinge determinados patamares e que ele se torna mercadoria disputada, o planejamento sintonizado a esses mesmos preceitos busca agenciar esses espaços para venda, ao mesmo tempo alimentando e atuando a reboque da valorização fundiária, que cria um ciclo retroalimentado através da arrecadação de impostos de propriedade imobiliária. Ações do planejamento que reduzam o valor da terra em determinada região - como a oferta de habitação de interesse social - tendem a ser evitadas, e as ações planejadas tendem a seguir uma lógica de potencialização da valorização.

Em termos setoriais, a partir dos processos de reestruturação regional da indústria que levam a uma configuração metropolitana ampliada, na direção da cidade-região (MagaIhães, 2008; Lencioni, 2003), os serviços avançados se destacam como a principal vantagem comparativa das economias metropolitanas. Trata-se de um grande grupo de atividades altamente heterogêneo, que concentra a grande maioria dos empregos de alto nível de qualificação e renda na estrutura produtiva atual, sendo um setor cujo insumo principal é a mão de obra intelectual e cujos subsetores diversos são altamente interdependentes uns dos outros. As complementaridades com os setores industriais e primários são óbvias, e o crescimento econômico puxado por aquelas atividades traz impactos diretos nos serviços.

Desse modo, a localização torna-se um insumo fundamental nesses setores de ponta. Ao contrário do declínio de importância da geografia, muito discutido no período em que as novas tecnologias de comunicação e transportes começaram a se tornar mais acessíveis e generalizadas, reafirma-se justamente o contrário, ou seja, a sua centralidade no capitalismo. Nos termos da abordagem de Harvey em diversas de suas obras, a competição por espaço torna-se uma busca por vantagens competitivas que podem resultar em maior poder de mercado na direção de uma condição monopolista (ou de concorrência monopolista), ${ }^{2}$ através da própria vantagem locacional adquirida (que tende a envolver, na economia imaterial urbana, uma vantagem relacional, ligada aos vínculos relacionais que a proximidade pode fornecer). Nisso, o solo urbano situado nos 
territórios vinculados a esse nexo econômico de alto valor agregado ganha poder de mercado e se torna uma oferta inserida num padrão de concorrência monopolista ainda mais acentuado que anteriormente, ampliando sua capacidade de extração de renda da terra, fundamental no processo de aprofundamento da financeirização do mercado imobiliário - que se torna, ao fim e ao cabo, a financeirização da própria cidade.

0 insumo produtivo fundamental da economia imaterial urbana, da qual os serviços avançados fazem parte e que tangencia, em partes, a produção cultural de forma ampla, é o conhecimento (técnico, científico, aplicado) e a informação. 0 elemento capaz de potencializar a produtividade deixa de ser o coeficiente técnico mobilizado nas máquinas e na tecnologia aplicada à produção e passa a ser um adendo do trabalho vivo. Nesse sentido, há uma tendência pós-industrial nessas geografias econômicas bem delineadas, mas ressaltamos que elas se inserem numa divisão espacial do trabalho em constante aprofundamento e em redes ampliadas e que se organizam na escala da globalização, nas quais a acumulação industrial permanece central na produção de valor, na organização da produção e na consequente definição de investimentos.

É importante ressaltar a heterogeneidade que o trabalho intelectual pode assumir na prática: pode ser massificado, automatizado, estandardizado; pode ser liberado, criativo embora instrumentalizado; pode ter coeficientes variados de complexidade e de conhecimento especializado, abarcando, assim, ocupações, setores e atividades tanto na ponta da geração (ou fonte de canalização) de alto valor agregado, como naquelas que se situam no chamado circuito inferior da economia urbana, caracterizadas por baixos rendimentos/remunerações e por uma situação de frequente precariedade e instabilidade. Esse trabalho, para Hardt e Negri (2009), bem como para Lazzarato e Negri (2001) envolve um aspecto biopolítico e é realizado pelo agenciamento do corpo na produção de forma distinta do trabalho industrial, que, por sua vez, envolve presença física e compartilhada com insumos materiais, máquinas e outras estruturas físicas. 0 trabalho imaterial torna-se o próprio pensar, o saber, a produção intelectual, emocional e subjetiva, não se separando, assim, da própria vida e, sendo por isso, produção biopolítica (ibid., pp. 30 e 47).

É, nesse sentido, que surge a noção da cidade como "fábrica social", pois é nela onde se concentram esse transbordamento e essa mescla do trabalho com a vida, a partir da sua generalização no espaço social da metrópole, que se torna "usina biopolítica" (Hardt e Negri, 2009, p. 251). Hardt e Negri enxergam a produção contemporânea não somente como uma bioeconomia, um trabalho biopolítico, em função de sua mescla com o espaço-tempo da própria vida, mas veem, no comum já existente, uma ampla base de produções de afetos, de conhecimentos, de subjetividades, de técnicas e de informações da qual a república da propriedade e o capital extraem renda através de seus cerceamentos. Assim, o trabalho biopolítico transborda, é transbordante por natureza, uma vez que tais tentativas de cerceamento já não são totalmente capazes de fazê-lo e, nesse transbordo, há vazamentos na direção da construção do comum. Trata-se assim, para aqueles autores, de romper esse elo de dominação e sucção de renda e de promover o comum liberto através da sua produção já existente, que o 
capitalismo cognitivo e a produção biopolítica já constroem diariamente de forma potencialmente não excludente. No entanto, a ideia de que a extração de renda de forma difusa toma as rédeas do processo amplo de acumulação - e nisso se torna dominante na própria economia urbana, em detrimento do valor propriamente dito, agenciado diretamente no âmbito interno à produção como na teorização marxista clássica - envolve certa sinédoque no erro (de se tomar a parte pelo todo), ligado à identificação e à projeção exagerada de uma tendência real, mas que convive em conjunto e não substitui a proeminência do valor produzido e canalizado através do lucro advindo da produção, mesmo que não seja necessariamente material/industrial. É importante não confundir a primazia contemporânea das finanças com uma tendência de a renda tornar-se também primaz diante dos lucros, pois o financeiro é alimentado por ambos. Propõe-se, assim, o reforço mútuo entre estes, e tal proeminência do capital financeiro resolve o conflito clássico entre o rentismo e o capital produtivo, ao agenciar e controlar ambos de forma simultânea.

No que diz respeito ao padrão de produção do espaço na escala intraurbana e à dimensão da apropriação, há uma tendência inicial da reestruturação (pós-crise da metrópole fordista keynesiana) do espaço urbano que leva na direção do cerceamento e da privatização, ${ }^{3}$ e do definhamento do espaço público de apropriação aberta, livre e democrática. Mas não é necessariamente o caso: há uma conciliação conservadora entre os arquétipos de Jane Jacobs e Robert Moses no urbanismo neoliberal (Larson, 2013), em que os processos de gentrificação que operam sobre o urbanismo de pequena escala da mistura de usos, das calçadas fartas para pedestres, etc. retiram em grande parte o caráter democrático que se acreditava vinculado a essa forma de urbanização anterior ao modernismo, como atesta 0 próprio processo de haussmanização em seu caso original parisiense. Ou seja, mesmo no padrão urbanístico situado fora dos elementos modernistas que se fazem presentes e persistentes no funcionalismo vinculado ao cerceamento (que o novo urbanismo busca criar de forma alegórica dentro das próprias bolhas cercadas e que aparece também em contextos de espetacularização mais explícita, como é o caso do espaço aberto das operações urbanas recentes), o processo excludente entra em cena através da gentrificação. No entanto, como também demonstrado na trajetória da experiência de Paris pós-Haussmann, o "espaço público oposicional" (Negt, 2007) permanece decisivo nessas localidades, não sendo essas dinâmicas de elitização suficientes para anular o caráter inerentemente político da produção do espaço urbano em constante disputa. Ilustra esse aspecto com clareza a centralidade da repressão policial na hegemonia urbana baseada no bloqueio do aprofundamento democrático, configurando um regime de violência estrutural em que a ordem se estabelece fundamentalmente a partir do emprego da força (Graeber, 2004, pp. 71-72).

\section{Financeirização da cidade e endividamento como mecanismo de controle}

Em paralelo ao avanço do neoliberalismo em escala ampla, o capitalismo contemporâneo é marcado por uma expansão do setor 
financeiro e em sua proeminência política em relação a outros setores e grupos de interesse anteriormente mais fortes nos espaços de disputa entre capitais. Em termos tanto políticos quanto econômicos, as finanças tornam-se o principal grupo de atividades que compõem a economia imaterial urbana contemporânea. Nesse processo, cria-se a possibilidade de o mercado de capitais entrar de formas diversas em inúmeros setores de atividade, ampliando sua atuação e sua vinculação - construindo canalizações de mais-valor na sua direção -, no limite da direção da totalidade das atividades econômicas. Há também uma tendência à formação de monopólios e cartéis em setores diversos, como apontado em 1910 na obra clássica de Rudolf Hilferding (1985 [1910]) a respeito do capital financeiro e de seus vínculos com o capitalismo monopolista, devido ao fato de haver interesse de que as finanças, operando no comando e controle de firmas diversas e concorrentes, unam-se num só agente, com economias de escala ampliadas, e um poder de mercado fortalecido.

A financeirização pode ser entendida, desse modo, como a construção ampliada e diversificada desses canais por onde passam fluxos de mais-valor, lucros e renda advindos de fontes diversificadas e geograficamente difusas. Tais rendimentos remuneram capitais também angariados e mobilizados de forma ampliada, como na criação de fundos de investimento amplamente disponíveis para correntistas de grandes bancos comerciais ou na mobilização de fundos de pensão com grandes quantidades de recursos disponíveis para investimento de longo prazo. Essa presença crescente e o ganho de protagonismo das finanças em busca de oportunidades de investimentos fazem com que sua atuação se espalhe e passe a operar na produção de condições para sua própria entrada em domínios anteriormente isolados de sua influência - o que é o caso das parcerias público-privadas na gestão pública obrigada a buscar recursos alternativos em função das restrições orçamentárias produzidas pelo seu próprio endividamento, gerando oportunidades de investimento privado em estruturas coletivas que vão desde estádios de futebol de propriedade pública até o caso extremo dos presídios.

A difusão, a extensão e o aprofundamento desses canais de extração de valor e renda agenciados pela proeminência do setor financeiro e incentivados diretamente pelo Estado ocorrem através de redes de agentes interligados e situados em esferas diversas de atuação. 0 produto desse processo também é a formação de redes, atuando como uma tecnologia social mobilizada na extração difusa e de canalização de valor e renda através das finanças e em sua direção. A profusão de setores de ponta, internos às finanças, que atuam na busca por oportunidades de investimento em territórios ampliados e diversos da acumulação no âmbito da economia real, seja nos bancos de investimento de portes diversos, seja nos fundos de private equity que se multiplicam em escala e escopo, é exemplo dessa engenharia das redes de canais que efetivam as ligações difusas com as finanças, nesse caso no âmbito da produção, envolvendo a extração de valor. Padrões semelhantes ocorrem na ponta do crédito, na busca por novas formas e mercados para a ampliação da concessão de financiamentos de forma ampla e do endividamento, que também constituem redes semelhantes, mas no domínio da renda, na remuneração de juros ao capital 
financiador. Há, assim, uma transformação de ordem qualitativa nas finanças, acompanhada de um aumento significativo de sua atuação através da expansão do próprio crédito. As consequências de tal fato são de grande envergadura, sendo a própria crise financeira de 2008 diretamente ligada a esse aprofundamento da financeirização e à ampla diversificação de novas formas de atuação das finanças.

A partir desse nexo, o neoliberalismo urbano baseia-se numa lógica econômica que promove a financeirização da cidade, que fomenta e pega carona na valorização imobiliária e se agencia através de um fortalecimento do poder de fogo dos capitais imobiliários na conformação da política urbana e de uma forma de planejamento voltada para o abastecimento desse mecanismo através de projetos e planos urbanos diversos, sendo o processo de gentrificação a frente de expansão territorial de um meio urbano ultra valorizado que esse modelo de planejamento busca promover. Os serviços avançados que compõem a economia urbana nos pilares desse mercado imobiliário inflado abarcam atividades de apoio direto à organização do comando e controle da esfera produtiva, que se posicionam na ponta de canais diversos de valor extraído da produção, da distribuição e do consumo, recebendo fluxos de lucros e dividendos oriundos de capitais de diversas naturezas e de grande alcance territorial. 0 setor financeiro é a expressão máxima desse padrão de canalização de valor advindo de fontes diversificadas, abarcando atividades desde a indústria até a mobilização da renda da terra, que permite uma criação de vínculos extrativos de valor com a economia urbana de forma ampla e difusa. Sua hegemonia passa pelo poder de criar tais vínculos e estruturas de canalização de mais-valor na sua direção.

Se essa nova economia urbana é sustentada por fluxos de renda em parte advindos de outros espaços, o setor imobiliário cria um mecanismo semelhante em relação aos serviços avançados: apreende parte dos valores que ele extrai de uma base produtiva maior através da remuneração da renda da terra, criando oportunidades para o capital rentista organizado no setor imobiliário em novos patamares. $\mathrm{E}$, nesse processo, esse espaço urbano transformado em mercadoria, produto do capital imobiliário, torna-se também um produto financeiro, um título lançado no mercado e que concorre com outros papeis - desde ações até títulos de dívida pública ou derivativos diversos. Nisso, há um processo de financeirização do espaço urbano que é mais aprofundado que a simples vinculação do imobiliário ao mercado de capitais, pois trata-se de uma abertura para que o setor financeiro atue na própria cidade transformada em fábrica social, tendo a renda da terra como uma forma de canalização de valor da economia imaterial urbana do terciário avançado.

Como proposto por Hardt e Negri, "a metrópole está para a multidão da mesma forma que a fábrica estava para a classe operária industrial" e, enquanto "a fábrica gerava lucro, a metrópole gera renda" (2009, p. 250), na forma da renda da terra capturada nos canais difusos produzidos pelo capital imobiliário ou sob outras entradas da financeirização no espaço econômico dessa fábrica social metropolitana. Adicionando nossa perspectiva crítica já delineada acerca dessa visão (que não retira a centralidade da produção de valor no abastecimento da própria renda, mas não somente na produção material), há um processo de 
canalização do valor produzido na metrópole no seguinte encadeamento: da esfera produtiva como um todo na direção dos serviços avançados (que já inclui, nesse elo, grandes porções do setor financeiro), para a renda da terra que sustenta materialmente a localização dessas atividades, interdependentes entre si e por isso altamente dependentes dos núcleos metropolitanos, para o mercado imobiliário financeirizado. No contexto da metrópole brasileira, a forte desigualdade no acesso à terra cria uma condição de desigualdade entre investimento e dívida, engendrando relações sociais de financeirização, sendo o acesso à propriedade privada do imobiliário uma forma de ampliação do alcance dessas relações de endividamento, que correspondem ao fim e ao cabo à produção de vínculos de remuneração rentista.

Tendo em vista que o próprio solo urbano se torna mercadoria de um mercado em concorrência monopolista - ou seja, com grande poder por parte dos ofertantes de definição de seus próprios preços e, portanto, com grande capacidade de angariar maiores rendimentos -, a política urbana passa a atuar em função da maximização do somatório dessa valorização fundiária, parcialmente em função do imperativo da busca por vantagens comparativas como forma de promover o crescimento econômico urbano. 0 potencial de criação de renda fundiária diferencial, a partir de atributos adicionados tanto fisicamente quanto no fortalecimento da própria densidade relacional apropriada pelo terciário avançado, tende a ser aproveitado ao máximo possível por parte desses agenciamentos. 0 resultado é um reforço da tendência excludente inerente à cidade capitalista, na medida em que essa busca pela maximização da valorização agregada do solo urbano tende a lançar a população de baixa renda para áreas distantes, pois sua presença em locais de grande potencial de valorização tende a diminuir esse potencial. Também se produzem espaços como ativos financeiros comercializáveis que entram em circuitos especulativos separados do uso dos imóveis, resultando num aumento da quantidade de unidades residenciais e comerciais vazias, de propriedade de investidores e especuladores imobiliários, apostando na valorização de médio e longo prazo de seus imóveis em patamares superiores a outros ativos financeiros quaisquer.

0 processo de financeirização, entendido também como uma tomada da hegemonia por parte do capital financeiro, envolve um enfraquecimento do conflito clássico entre agentes rentistas e o capitalismo produtivo, que gera consequências políticas importantes para esse nexo de fomento à valorização fundiária vinculado à financeirização da cidade. Como o setor financeiro cria vínculos de canalização de mais-valor com um amplo leque de atividades econômicas, que na metrópole inclui tanto a economia imaterial urbana que ajuda a sustentar a renda da terra quanto os próprios setores do capital imobiliário que a sugam do circuito de valorização através da produção (ainda que majoritariamente intangível), a hegemonia do setor financeiro esvazia o conflito entre esses dois grupos subsumidos.

É interessante notar como em grandes cidades dos países de centro essa dinâmica se faz presente no esvaziamento de formas diversas de políticas públicas estruturadas pela hegemonia anterior do capital produtivo na direção de minimizar a renda da terra (através do provimento direto de habitação de interesse social, do controle de aluguéis, do aluguel 
social provido pelo Estado, do fomento a cooperativas de habitação popular não gerenciadas pelo Estado, dentre outras modalidades, ainda presentes, com menor poder de fogo diante da pujança do processo de neoliberalização, em diversas localidades - sobretudo na Europa ocidental, nos países escandinavos e em outros formatos, mais diretamente ligados ao socialismo autoritário e centralizado, na China). Trata(va)-se de um modo de atuação do Estado keynesiano diretamente associado ao capital industrial que encara a renda da terra nos termos do conflito clássico com a aristocracia improdutiva antiga, cujos landlords sugavam parcelas da renda gerada na produção simplesmente em função de suas inserções como proprietários. Reduzir ao mínimo possível a renda da terra sugada através de políticas que resultem, ainda que indiretamente, em menor valorização fundiária como um objetivo público de bem-estar social era, nesses termos, uma política keynesiana de potencialização da demanda efetiva que se revertia aos capitais produtivos (sobretudo industriais) na forma do consumo mais elevado. Ou seja, não se tratava ali de uma política anticapitalista - o que não seria verdade nas condições atuais, no contexto da hegemonia do capital financeiro que promove ativamente a valorização fundiária como parte de uma apreciação geral de seus ativos e, logo, de seus rendimentos. Considerar o caso brasileiro em que tal conflito entre landlords aristocratas e o capital (industrial) produtivo nunca foi forte o suficiente ao ponto de se traduzir numa formatação de políticas públicas a favor do segundo grupo é fato bastante revelador das especificidades de nossa formação social e, nestse caso, dos grupos que compõem seus estratos de maior poder econômico e político. A ausência histórica dessa disputa envolve consequências cristalizadas tanto em nossos ambientes construídos na metrópole quanto na paisagem social do meio rural (ainda) marcado por um altíssimo grau de concentração fundiária.

De forma análoga à ideia da fábrica social, a financeirização, e sua resultante proliferação da figura do endividado pelo espaço social, atua na difusão de uma relação de dominação e de exploração do trabalho alheio (que envolve uma remuneração monetária intertemporal por parte do endividado), não mais limitado ao contato direto e bem delineado no tempo-espaço entre capital e trabalho, mas difundido e espraiado tanto temporal quanto espacialmente. A relação social através da renda dos juros complementa aquela baseada na remuneração do capital produtivo nesse cenário e se prolifera para além da renda da terra alimentada pelo avanço da economia imaterial urbana, difundindo-se de outras formas (Hardt e Negri, 2012, p. 16).

Para Hardt e Negri (ibid.), o endividado emerge como uma das figuras subjetivas emblemáticas da crise, em conjunto com o mediatizado, o securitizado e o representado. 0 endividamento é visto por aqueles autores, em termos deleuzoguattarianos, como uma forma de controle e disciplinamento, através da progressiva formação de uma "consciência infeliz" que carrega um senso de responsabilidade e culpa pela própria dívida. Na perspectiva spinoziana daqueles autores, esse tipo de vínculo negativo tem o efeito disciplinador/ controlador de diminuir a potência criativa do pobre, do trabalhador, do subalterno, essencial para a sua própria produção de autonomias e formas de saída dessas relações. Trata-se, 
também, de uma forma de se conduzir novas rodadas do processo de acumulação primitiva, de formação de uma oferta de mão de obra barata através de dinâmicas que Harvey (2004) denomina despossessão, que significa, ao fim e ao cabo, a destituição de outras alternativas de sobrevivência em grupos cuja única opção é a venda de sua própria força de trabalho. Além do aspecto moral que carrega a relação devedor-credor, o endividado tende a aceitar trabalhar por menos, tem possibilidades menos elásticas de busca por e criação de alternativas de inserção e sobrevivência e se torna mais avesso ao engajamento em atividades que colocam seu emprego em risco, tal qual a própria mobilização trabalhista.

Passamos, nesse ponto, ao tema do comum - como um contraponto radical à neoliberalização da sociedade e do espaço. Nessa passagem, é necessário estabelecer um pressuposto, como em Magalhães (2016), que os pilares desses processos são constituídos por elementos estatais e jurídicos. Não há neoliberalismo sem Estado. Trata-se de um modelo de governo e de estruturação do poder na sociedade que opera a partir de ajustes regulatórios que abrem terreno para processos econômicos diversos. Problematizar esses pilares implica discutir não somente os embates e contradições que surgem (e que a história contemporânea tem demonstrado ser inerentes) entre democratização e neoliberalização, mas, para além, aponta para a necessidade de se pensar em construções alternativas coletivas que não passem necessariamente pelo âmbito do Estado - que este tenderá a reprimir, na medida em que elas demonstrem potências de enfraquecer relações sem as quais o hegemônico não se sustenta.

\section{A metrópole do comum}

\author{
Além do público e do privado: \\ a alternativa do comum
}

Referindo-se a bens e recursos abertos e compartilhados, como a riqueza material da natureza (o ar, a água, os frutos do solo, etc.) ou a riqueza imaterial da produção social (conhecimentos, culturas, linguagens, etc.), o comum delineia a construção de novas formas democráticas de produção e gestão de recursos compartilhados, contra sua apropriação privada ou pública (Hardt e Negri, 2009). Não obstante, o comum não é uma coisa ou um recurso em si, diz Bollier (2014, pp. 175-176), mas um recurso compartilhado e associado a uma dada comunidade e a protocolos, normas e valores criados para a sua gestão coletiva, com especial atenção a questões de acesso igualitário, uso e sustentabilidade. Ou seja, nada é comum por natureza: um recurso é tornado comum por uma prática coletiva de gestão e cultivo (Dardot e Laval, 2015). 0 comum como substantivo envolve muito mais a construção de um princípio político do que os recursos em si ou essa produção de um conjunto de bens e serviços abertos à apropriação coletiva.

Os recursos comuns têm sustentado sociedades humanas por um longo tempo, mas a formação - e contínua expansão e reprodução - do modo capitalista de produção, baseado na propriedade privada e na relação mercantil, foi (e ainda é) alcançada pelo cercamento, expropriação e mercantilização do comum. Marx (2013 [1867]) e Polanyi (2012 [1944]) revelaram que a gênese histórica do capitalismo, sistema econômico de mercado baseado na separação 
entre produtores e seus meios de produção, encontra-se no processo de cercamento - privatizações - das terras comunais na Inglaterra. Os direitos costumeiros e regimes de propriedade comunal da terra e dos recursos, cultivados por séculos, foram violenta e/ou institucionalmente destruídos e eclipsados, dando lugar à hegemonia da propriedade privada e ao desenraizamento da economia das demais esferas sociais. Mas o cercamento do comum não foi um fenômeno histórico restrito à Europa: a colonização do planeta pelo Ocidente deu-se também como um violento processo de despossessão e apropriação colonial de terras e recursos que eram usados comunalmente por outros povos e que constituíam o fundamento territorial da sua sobrevivência, material e simbólica. No Brasil, por exemplo, a implantação do projeto colonial português deu-se pela sistemática apropriação, exploração e destruição das terras, meios de vida e saberes comuns dos inúmeros povos que aqui viviam (Ribeiro, 2006).

Tampouco o assalto global ao comum é apenas um registro histórico: ele prossegue a todo vapor nas fronteiras de avanço da acumulação capitalista no mundo pós e neocolonial. Conforme visto na sessão acima, em decorrência da expansão do capitalismo neoliberal, desde as últimas décadas do século $X X$ pode-se mesmo falar de um novo ciclo de cercamentos massivos do comum em escala global, de mercantilização da natureza que se dá como uma acumulação por despossessão (Harvey, 2004). A expropriação da nossa riqueza comum se dá hoje, nos termos de Bollier (2014), sob formas tão diversas quanto o patenteamento de genes e as formas de vida, a extensão das leis de direitos autorais sobre a criatividade e a cultura, a privatização da terra e das águas, as tentativas de transformar a Internet livre em um mercado de propriedade fechada, a mercantilização de infraestruturas urbanas e espaços públicos, etc. Nas palavras de Linebaugh (2014), o processo de cercamento é o antônimo histórico do comum. Ontem e hoje.

As resistências aos novos cercamentos e privatizações perpetrados pelo capitalismo neoliberal revelaram um mundo de propriedades e relações comunais que se imaginava extinto ou não valorizado: e mais, chamaram a atenção não apenas para o fato de que 0 comum tenha sobrevivido, mas de que novas formas de cooperação social estejam continuamente a ser produzidas. No caso do século passado, a ideia "pré-moderna" do comum reapareceu como um potente conceito teórico e discurso político, apontando alternativas para além da dicotomia Estado-mercado, do público-privado. Como apontado por uma miríade de autores (Bollier, 2014; Dardot e Laval, 2014; Federici, 2010; Hardt e Negri, 2009; e Linebaugh, 2014), hoje o comum contribui para dar sentido, potencializar e conectar uma pluralidade de lutas e resistências anticapitalistas em todo o mundo.

Quais as razões por trás da (re)apropriação dessa ideia supostamente arcaica? Por um lado, pode-se falar da necessidade de repensar e propor alternativas democráticas à falência soviética e dos demais socialismos reais, noutros termos, do modelo estatista de revolução que, por décadas, havia servido de orientação às tentativas radicais de construir uma alternativa ao capitalismo; por outro, há o crescente reconhecimento e indignação sociais ante os efeitos deletérios da total subordinação da natureza e da vida ao capital, da extensão da lógica neoliberal da competição 
à toda a sociedade (Dardot e Laval, 2014; e Federici, 2010).

Se a crise do Estado keynesiano de bem-estar social e a do Estado soviético tornaram evidentes os limites do intervencionismo, a crise global do capitalismo financeiro detonada em 2008 tem colocado em xeque a panaceia neoliberal das "soluções de mercado". Sob o neoliberalismo, que ataca qualquer foco de resistência à norma geral da concorrência, o Estado é tanto alvo de políticas que visam a enquadrá-lo nessa lógica, tornando-o mais "competitivo" e "eficaz", quanto é ele mesmo que organiza o seu desaparecimento - via privatizações, desregulamentações, etc. - em favor do privado. Dardot e Laval (2014) consideram que, sob tais condições de hibridização generalizada entre o Estado e o mercado, não cabe mais opor frontalmente o público ao privado.

Mas a emergência contemporânea do comum não se dá apenas no plano político, tendo importantes implicações no âmbito das ciências humanas e sociais. Segundo Wall (2014), o debate teórico sobre o comum envolve complexas nuances epistemológicas e ontológicas e atravessa inúmeras disciplinas (como antropologia, ecologia, direito, geografia, história e economia, dentre outras). Grosso modo, os estudos sobre o comum dividem-se em duas grandes abordagens: uma desenvolvida no âmbito das ciências sociais mainstream, sob a égide do pensamento econômico liberal; e a segunda, formulada nos termos da teoria crítica, em estreita proximidade com a crítica da economia política.

A primeira abordagem é tributária dos trabalhos da economista Elinor Ostrom (1990), que foi pioneira em sistematização e análise de evidências antropológicas, sociológicas e históricas de inúmeras experiências bem-sucedidas de gestão coletiva de recursos comuns (common-pool resources) ao redor do mundo (florestas, pastos, pesqueiros, etc.). Ao revelar uma rica mistura de institucionalidades coletivas distintas das soluções privatistas de mercado e do intervencionismo estatal, Ostrom escancarou os limites da falaciosa narrativa da "tragédia do comum" traçada por Hardin (2009 [1968]), que previa que qualquer recurso comum de livre acesso estaria fadado à superexploração. Essa perspectiva aberta por Ostrom teve muita repercussão no debate ambiental, principalmente por haver trazido à tona que a gestão de recursos naturais pelas próprias comunidades poderia ser mais sustentável, em algumas circunstâncias, do que a gestão pelo Estado ou pelo mercado.

Entretanto, a perspectiva aberta por Ostrom, circunscrita aos limites da economia liberal, acaba por reificar os recursos comuns como um tipo específico de bens complementares aos bens públicos e privados, e não a eles opostos, ofuscando, assim, as relações de poder; além de, por vias de um economicismo funcionalista centrado na maximização da utilidade individual, recusar-se a reconhecer que as pessoas possam ter motivações não-econômicas para cooperarem. As abordagens de cunho mais crítico sobre o comum tentam levar em consideração essas questões, tendo em vista que o comum é antes uma relação social e um conceito político do que um bem ou um regime coletivo de propriedade. Ademais, partem do entendimento de que o comum é antagônico ao capital, e que o capitalismo, onde quer que se instale, o faz cercando e expropriando o comum, minando as possibilidades de reprodução e 
produção social fora do âmbito compulsório do mercado.

Dardot e Laval (2014) reconhecem, na obra de Michael Hardt e Antonio Negri, a primeira teoria de cunho crítico do comum. Como visto, o argumento central de Hardt e Negri (2009) é que a indústria e o trabalho material já não detêm a hegemonia sobre a economia e a sociedade, perdendo espaço nas últimas décadas para a produção biopolítica (ou imaterial, cognitiva) de ideias, linguagens, afetos, códigos, imagens, etc. Ao contrário dos recursos naturais, o comum imaterial produzido em rede tem reprodutibilidade e compartilhamento indefinidos, potencialmente escapando às circunscrições da propriedade privada. Portanto, uma sociedade baseada no comum já estaria em gestação pela crescente introdução de elementos cognitivos comuns no coração da produção capitalista. Abre-se, portanto, um espaço para gestação do comunismo, tal qual defendido por Marx, por meio das próprias contradições agenciadas pelo capital. Tal projeto político atravessa diagonalmente a oposição binária entre socialismo e capitalismo e entre seus regimes de propriedade correspondentes: o público e o privado, excludentes do comum. 0 lócus da produção de riqueza extravasa as fronteiras da fábrica para recobrir e mobilizar toda a vida, deslocando-se para a metrópole, usina biopolítica do comum.

Entretanto, o foco de Hardt e Negri no comum imaterial deixa de lado o comum gestado em margens e periferias do capitalismo, assim como os recursos "naturais" e a própria terra, ainda essenciais à sobrevivência de grande parte da população mundial não integrada aos circuitos mais avançados da economia. É contra esse silêncio e ausência que Federici
(2010) vai defender que a política do comum seja encarada a partir de uma perspectiva feminista constituída em torno da vida cotidiana, do trabalho de reprodução social (trabalho doméstico não remunerado, atividades não monetizadas, produção de valores de uso, etc.), estruturalmente a cargo das mulheres. As lutas femininas pelo comum mostram como a coletivização e o compartilhamento dos meios materiais de reprodução constituem a primeira linha para desligar nossa reprodução do mercado capitalista, tornando-a mais cooperativa. Também para De Angelis (2007), essas práticas de reprodução (que podem ser orientadas por relações e valores, como a dádiva, a reciprocidade, a solidariedade e a cooperação) constituem um comum "fora" e antagônico ao capital.

Uma outra perspectiva crítica importante sobre o comum foi formulada por Dardot e Laval (2014), para os quais o comum, no substantivo, corresponde ao princípio político segundo o qual a participação em uma atividade coletiva constitui o fundamento da coobrigação política. 0 comum não se confunde com os recursos comuns, ou com o bem comum. Deve-se falar, portanto, de comuns para designar não aquilo que é, naturalmente ou por direito, comum, mas aquilo que é investido por uma atividade de compartilhamento. Assim, há comuns de espécies muito diferentes em função do tipo de atividade que os instituem (comuns fluviais, florestais, de produção, de conhecimento, etc.). É a atividade que "torna comum" a coisa, inscrevendo-a em um espaço institucional mediante a produção coletiva de regras específicas. Dardot e Laval defendem que esse princípio do comum emergiu no seio das próprias lutas e movimentos em contraposição à racionalidade neoliberal, à extensão da 
lógica proprietária a todas as esferas da vida e da natureza, já que a propriedade privada, base filosófica, jurídica e econômica do capitalismo, retira as coisas do uso comum e corrói a cooperação. Portanto, o comum deve ser definido por uma norma de inapropriabilidade e disponibilidade das coisas contra a apropriação exclusivista e depredadora, seja ela pública ou privada. Trata-se, enfim, da experimentação de um direito de uso coletivo contra o direito de propriedade, mais do que da reivindicação de uma propriedade coletiva.

\section{0 comum urbano: a cidade contra o neoliberalismo}

Como visto, as abordagens teóricas e os estudos históricos e antropológicos disponíveis sobre o comum, seja em sua vertente liberal institucionalista ou nas suas formulações mais radicais, abarcam em seu registro empírico tanto os recursos naturais e terras comunais quanto o comum imaterial e digital. Logo, em um movimento geográfico e epistemológico de consequências não desprezíveis, salta-se dos domínios da natureza e do campo ao universo cibernético e informacional, passando ao largo da realidade urbana. Ao mesmo tempo que a urbanização planetária se afirma como tendência irreversível, os pesquisadores do comum não se propuseram - salvo notáveis exceções a discutir mais detidamente como seria olhar para a urbanização contemporânea a partir do comum, nem a se interrogar sobre como se produzem espaços comuns na metrópole.

Muito já foi dito e escrito sobre a metrópole como o espaço por excelência do indivíduo atomizado, desgarrado de quaisquer laços comunitários, espaço em que esse mesmo indivíduo - produto da nossa modernidade - é obrigado a trafegar anonimamente com certa indiferença e segundo seus interesses particulares ou com aquela atitude blasé de que falava Simmel (1973), para não se deixar ser arrebatado e subjetivamente dilacerado pelos desconcertantes estímulos das ruas e do mundo da mercadoria. A urbanização é usualmente tomada como força anticomum, na medida em que se reconhece a formação da metrópole moderna (industrial) como o outro lado da moeda do processo histórico de cercamentos e despossessões que assolou o campo nos albores do modo de produção capitalista.

Entrementes, inúmeros movimentos, coletivos e ativistas, ao redor do mundo invocam a ideia do comum para orientar suas ações de contestação, apropriação e transformação coletiva da cidade; noutros termos, sua luta pelo direito à cidade (Lefebvre, 2008 [1968]) em oposição à intensificação dos cercamentos, privatizações e despossessões decorrentes da neoliberalização do urbano. Segundo Foster e Laione (2016), a linguagem do comum vem sendo mobilizada para reivindicar e proteger um conjunto de recursos e bens urbanos que poderiam ser mais amplamente compartilhados entre os habitantes da cidade.

Esses autores identificam a existência do potencial para uma ampla gama de comuns em diferentes escalas do espaço urbano, tais como o próprio solo urbano (particularmente terras vagas e não construídas), uma variedade de espaços abertos e de infraestruturas (como as ruas) e a reivindicação ao uso e ocupação de edifícios e estruturas, públicos ou privados, abandonados ou subutilizados. Outros pesquisadores também atentaram para esse fato 
e puseram-se a investigar espaços que são ou poderiam ser comuns: espaços públicos, calçadas, hortas comunitárias, parques, centros culturais autogeridos, transporte público, energia e água, moradias coletivas, etc. (Dellenbaugh et al., 2015; e Kip, 2015). Certos espaços na metrópole brasileira que encerram práticas solidárias, compartilhadas, etc., principalmente nos territórios populares e periféricos (embora não todos), podem também ser considerados comuns urbanos.

Ainda que a terra urbana esteja hoje profundamente mercantilizada e subsumida aos mais avançados circuitos da produção do espaço pelo capital, de modo algum ela deixa de ser um dos fundamentos da reprodução da vida coletiva: daí as várias lutas em torno de espaços urbanos que contestam certas configurações de direitos de propriedade resistindo ao cercamento dos comuns (Blomley, 2004), e as muitas reivindicações para tornar a terra um comum no qual as necessidades sociais (valor de uso) seriam favorecidas em detrimento de necessidades puramente políticas e econômicas (valor de troca).

Harvey (2012) distingue entre, de um lado, espaços públicos e bens públicos e, de outro, os comuns. Os processos de industrialização e urbanização exigiram que o Estado nacional e as administrações públicas locais se encarregassem de garantir bens públicos urbanos, tais quais habitação social, saneamento, pavimentação, água, saúde, educação, espaços abertos, etc. Ainda que tais bens públicos possam contribuir para as qualidades do comum, é preciso ação política dos cidadãos para deles se apropriar, protegê-los, fortalecê-los e torná-los efetivamente comuns. Não é esse o caso das praças apropriadas para manifestações políticas (Praça Syntagma, Praça, Tahrir, Plaza de Catalunya)? Portanto, proteger o comum exige também que se proteja o fluxo de bens públicos que sustentam a vida urbana, contra privatizações e cercamentos neoliberais.

Para Lefebvre (2008 [1968]), a cidade é uma obra coletiva, calcada no uso (e no valor de uso), em detrimento da mercadoria, do valor de troca. Socialmente produzida, a cidade é diferente de todos os demais produtos: o que lhe dá especificidade é o primado do valor de uso sobre o valor de troca. Na cidade capitalista, esse valor de uso da cidade é eviscerado pela lógica de mercado e pela difusão da propriedade privada (da terra, dos imóveis, do espaço, etc.), daí a luta pelo direito à cidade, pelo uso e apropriação coletiva do espaço. Mas não é a própria cidade um bem ou recurso comum que passa a ser objeto das mais diversas apropriações, investimentos e disputas? Não é ela também um caldeirão produtivo, espaço de concentração de capitais, meios de produção e força de trabaIho, ela própria uma força produtiva coletiva? Alguns teóricos valeram-se, ainda, da noção do comum urbano para se referirem à essa dimensão mais ampla da vida urbana, da experiência urbana coletiva, da potência que a cidade tem de provocar encontros e entrelaçar relações de comunalidade, da própria cidade como um bem ou recurso comum.

Foster e Laione (2016) reconhecem que 0 ímpeto principal por trás das contestações em torno de quem usa e se beneficia do espaço urbano (e que estão na origem de muitas experiências de comuns) reside no confronto entre a crescente privatização e mercantilização dos bens e recursos comuns na cidade neoliberal e os movimentos sociais urbanos que reivindicam não apenas um "direito" a este ou aquele 
recurso particular, mas o "direito à cidade" como direito à tomada de decisões democráticas sobre o espaço urbano como um todo.

Para Simone (2014), o comum urbano não é apenas uma coleção de coisas (edifícios, infraestruturas, espaços públicos, etc.) acessíveis a uma ampla gama de usos e atores, já que seu sentido reside principalmente nas relações e práticas mutáveis de comunalidade, de entrelaçamento entre diferenças, de compartilhamento e de complementaridade que são produzidas pelos residentes urbanos nos seus engajamentos cotidianos entre si e com a cidade. Também Hardt e Negri (2009), como já mencionado, consideram que a cidade não se reduz ao ambiente construído, pois é um dínamo de práticas culturais, circuitos intelectuais, instituições sociais e redes afetivas. Esses elementos do comum contidos na cidade não são apenas os pré-requisitos para a produção biopolítica, mas também seu próprio resultado. Nos termos dos autores, a metrópoles contemporânea é uma usina biopolítica do comum, tanto fonte quanto receptáculo da produção do comum imaterial, cognitivo.

Já Harvey (2012) considera que a cidade é o lócus em que pessoas de todos os tipos e classes se misturam, mesmo que de modo relutante e agonístico, para produzir uma vida comum, embora perpetuamente mutável e transitória. Entretanto, as comunalidades dessa vida urbana - comentadas por urbanistas e celebradas por amantes da cidade desde há muito - encontram-se demasiado ameaçadas pela onda neoliberal de privatizações, cercamentos, controles espaciais, policiamento e vigilância.
Ainda que muitas vezes não possa ser cercado (em sentido estrito), esse comum urbano é capitalizado e apropriado privadamente via renda fundiária. Para o autor, a urbanização capitalista realiza-se contraditoriamente como produção permanente de um comum urbano e como simultânea degradação e expropriação desse mesmo comum pela ação predatória do capital e do Estado.

Tonucci Filho (2017) considera que o comum urbano geralmente se afirma nas práticas socioespaciais insurgentes e contra-hegemônicas que povoam dobras e interstícios do espaço abstrato, em emergentes processos de apropriação e experimentação espacial que cultivam o sentido do uso, da obra e da diferença contra o valor de troca e a dominação, nas aberturas e desestruturações que desafiam as tentativas de manter a cidade "na linha". Nas metrópoles do Sul global, essa pluralidade de práticas urbanas comuns que escapam e/ou se contrapõem ao Estado e ao capital florescem num campo opaco e incerto demarcado pela instabilidade e abertura da periferia, na qual relações informais de reciprocidade e compartiIhamento sobrepõem-se às teias de subjugação da vida e do espaço.

Portanto, os comuns não são apenas o território de uma nova geração de grupos ativistas: nas metrópoles brasileiras, o fazer-comum há muito tempo encontra-se incorporado nas favelas, periferias e espaços - tais quais as ocupações de moradia (ibid.) - designadas aos pobres urbanos, devido ao entrelaçamento entre estratégias de sobrevivência, informalidade, engenhosidade coletiva e reprodução social. 


\section{Considerações finais}

Muitos dos processos metropolitanos contemporâneos - desindustrialização, gentrificação, financeirização, endividamento, onipresença do etos da competição, enfraquecimento e sucateamento de estruturas coletivas e o imperativo das soluções privadas e individuais para problemas de ordem pública, privatização dos espaços e infraestruturas públicas, dentre inúmeros outros - relacionam-se de formas diversas ao neoliberalismo enquanto forma de estruturação do Estado e dos aparatos de governo e exercício do poder na sociedade. Trata-se de um emaranhado de dinâmicas que tende à generalização da lógica da produção de mercadorias e da competição no mercado em domínios anteriormente restritos à sua penetração. 0 momento atual no Brasil é repleto de manifestações dessa lógica, que perpassa a nova rodada de reajuste neoliberal e readequação do aparato regulatório que inclui, além da simples retirada de direitos coletivos politicamente construídos e conquistados, a transformação do provimento público de serviços em terreno de expansão potencial para provedores privados (geralmente oligopolizados) de previdência, educação, saúde, etc. 0 processo de financeirização vem a reboque de forma direta através do ganho extraordinário de atratividade da previdência privada e indiretamente na demanda por crédito gerada pela necessidade de acesso aos demais serviços. Sendo terreno de grande concentração da oferta de tais serviços, as metrópoles abrigam parte substancial desses potenciais novos mercados, que se somam a um nexo de organização socioespacial já pautado pelo aprofundamento e pela generalização do mercado que atinge a própria produção do urbano em seu âmago.

Daí a relevância e a atualidade de se pensar a metrópole do comum contra a metrópole neoliberal. A lógica do urbano - definido por Lefebvre como o espaço da centralidade, do encontro e da produção de diferenças - pode se encontrar com a lógica do comum (o compartilhamento) contra a lógica da mercadoria, contra a ordem proprietária. Apesar de seus constrangimentos, da sua submissão ao Estado e ao capital, a cidade continua sendo um espaço generativo e contraditório onde variados tipos de recursos, bens e espaços comuns podem florescer, articular-se e fortalecer-se.

Da mesma forma que o presente argumento se pauta por uma postura de pluralismo teórico-metodológico dentro do campo assumidamente progressista, não buscamos indicar, de forma alguma, a proposição normativa das potências da construção do comum de forma unívoca. Trata-se de um terreno formador de alternativas radicais à neoliberalização da cidade e do espaço, em conjunto e cooperação com pautas ligadas à radicalização da democracia e às práticas agonísticas de transformação radical das instituições (Mouffe, 2013) - tema que transborda o escopo do argumento aqui delineado -, pois se o neoliberalismo urbano tem pilares fundamentais no Estado, sua transformação na direção de se abrir espaço para que o comum possa surgir e se reproduzir torna-se imprescindível.

0 exercício da hegemonia sustenta-se num conjunto ampliado de relações sociais, que envolve uma intrínseca assimetria de poder em relações de dominação e exploração. Rotas de fuga possíveis que criem alternativas e enfraqueçam tais vínculos tendem a ser 
diretamente reprimidas pelo agenciamento que opera e reproduz o hegemônico. Ou seja, é importante pensar a construção do direito ao comum, caso contrário os poderes que atravessam o Estado tendem a continuar impedindo violentamente sua constituição ainda enquanto potência. Se o neoliberalismo se constitui no espaço social como uma forma de exercício do poder hegemônico - dentre outras facetas interligadas -, as aberturas democráticas para a potência do comum passam necessariamente pela possibilidade de construí-lo sem a repressão direta do Estado, o que invoca a necessidade de sua ampla transformação para tal. Sustentamos a proposição de que o comum, a despeito de seus limites e contradições, é um potente mote aglutinador, capaz de prover direcionamento a um ampliado leque de pautas centrais na questão urbana contemporânea, de unir esforços e construções de possibilidades de transformação e alternativas diante do avanço das hegemonias neoliberais sobre a produção do espaço.

\section{João Bosco Moura Tonucci Filho}

Universidade Federal de Minas Gerais, Instituto de Geociências. Belo Horizonte, MG/Brasil. jontonucci@gmail.com

\section{Felipe Nunes Coelho Magalhães}

Universidade Federal de Minas Gerais, Instituto de Geociências. Belo Horizonte, MG/Brasil. felmagalhaes@gmail.com

\section{Notas}

(1) As críticas à ideia e à conceituação da cidade neoliberal propostas por Storper (2016), além de se construírem a partir de ataques à validade teórico-conceitual da própria noção de neoliberalismo, como tão recorrente nos campos dominantes e hegemônicos da ciência econômica e do jornalismo mainstream das últimas décadas, perdem de vista essa transescalaridade fundamental não somente do neoliberalismo urbano (que, consequentemente, não pode ser compreendido de forma adequada em abordagens restritas a escalas menores e suas respectivas instituições), mas da própria dinâmica neoliberal de forma ampla, que é fundamentalmente interligada à globalização e dependente de seus desdobramentos.

(2) Estrutura de mercado em que a oferta é caracterizada por produtos que são similares, mas com características distintas o suficiente para serem tratados como únicos, portanto sem concorrência, como é o caso dos imóveis. 
(3) Como no "urbanismo em bolhas" - produzido em larga escala na metrópole brasileira a partir do final da década de 1980, em certa medida em resposta às deteriorações do espaço público e ao aumento da violência urbana -, formado pela tríade condomínio fechado (não necessariamente horizontal) e com relações defensivas com seu entorno imediato, primazia dos automóveis e motocicletas, preferencialmente em vias expressas, e shopping centers. Esse modelo apropria-se, não necessariamente de forma consciente, de alguns elementos fundantes do urbanismo modernista, recusando as intenções voltadas à construção do espaço da esfera pública naquele contexto.

\section{Referências}

BLOMLEY, N. K. (2004). Unsettling the city: urban land and the politics of property. Nova York/Londres, Routledge.

BOLLIER, D. (2014). Think like a commoner: a short introduction to the life of the commons. Gabriola Island, New Society Publishers.

DARDOT, P. e LAVAL, C. (2014). Commun: essai sur la révolution au XXIe siècle. Paris, La Découverte.

DE ANGELIS, M. (2007). The beginning of history: value struggles and global capital. London; Ann Arbor, Pluto.

Dellenbaugh, M.; KIP, M.; BIENIOK, M.; MUlleR, A. K. e SCHWEGMANN, M. (orgs.) (2015). "Seizing the (every)day: welcome to the urban commons!". In: Urban commons: moving beyond state and market. Basiléia, Birkhäuser Verlag $\mathrm{GmbH}$.

FEDERICI, S. (2010). "Feminism and the politics of the commons". In: HUGHES, C.; PEACE, S. e VAN METER, K. (orgs.). Uses of a WorldWind, Movement, Movements, and Contemporary Radical Currents in the United States. Oakland, AK Press.

FOSTER, S. e LAIONE, C. (2016). The city as a commons. Yale Law \& Policy Review. New Haven, v. 34, n. 281, pp. 281-349.

GRAEBER, D. (2004). Fragments of an anarchist anthropology. Chicago, Prickly Paradigm Press.

HARDIN, G. (2009 [1968]). The tragedy of the commons. Journal of Natural Resources Policy Research, v. 1, n. 3, pp. 243-253.

HARDT, M. e NEGRI, A. (2009). Commonwealth. Cambridge, Harvard University Press. (2012). Declaration. Nova York, Argo-Navis.

HARVEY, D. (1982). Limits to capital. Londres, Basil Blackwell. (2004). O novo imperialismo. São Paulo, Loyola.

(2012). "The creation of the urban commons". In: HARVEY, D. Rebel cities: from the right to the city to the urban revolution. Londres/ Nova York, Verso.

HILFERDING, R. (1985 [1910]). O capital financeiro. Rio de Janeiro, Abril.

KIP, M. (2015). "Moving beyond the city: conceptualizing urban commons from a critical urban studies perspective". In: DELLENBAUGH, M.; KIP, M.; BIENIOK, M.; MULLER, A. K. e SCHWEGMANN, M. (orgs.). Urban commons: moving beyond state and market. Basiléia, Birkhäuser Verlag GmbH. 
LARSON, S. (2013). "Building like Moses with Jacobs in mind": contemporary planning in New York City. Filadélfia, Temple University Press.

LAZZARATO, M. e NEGRI, A. (2001). Trabalho imaterial: formas de vida e produção de subjetividade. Rio de Janeiro, DP\&A.

LEFEBVRE, H. (2008 [1968]). O direito à cidade. São Paulo, Centauro.

LENCIONI, S. (2003). A emergência de um novo fato urbano de caráter metropolitano em São Paulo: a particularidade de seu conteúdo socioespacial, seus limites regionais e sua interpretação teórica. In: X ENCONTRO NACIONAL DA ANPUR. Anais. Belo Horizonte.

LINEBAUGH, P. (2014). Stop, thief! The commons, enclosures and resistance. Oakland, PM Press.

LOJKINE, J. (1981). O estado capitalista e a questão urbana. São Paulo, Martins Fontes.

MAGALHÃES, F. N. C. (2008). Da metrópole à cidade-região: na direção de um novo arranjo espacial metropolitano? Revista Brasileira de Estudos Urbanos e Regionais, v. 10, n. 2, pp. 9-28.

(2016). O espaço do Estado no neoliberalismo: elementos para uma redefinição crítica. GEOgraphia (UFF), v. 18, n. 37, pp. 35-60.

MARTINS, J. de S. (2004). O cativeiro da terra. São Paulo, Hucitec.

MARX, K. (2013 [1867]). O capital: crítica da economia política: Livro I: o processo de produção do capital. São Paulo, Boitempo.

MOUFFE, C. (2013). Agonistics: thinking the world politically. Londres, Verso.

NEGT, O. (2007). L'espace publique oppositionnel. Paris, Payot.

OLIVEIRA, F. de (2003). Crítica à razão dualista; o ornitorrinco. São Paulo, Boitempo.

OSTROM, E. (1990). Governing the commons: the evolution of institutions for collective action. Nova York, Cambridge University Press.

PECK, J. e TICKELL, A. (2002). Neoliberalizing space. Antipode, v. 34, n. 3, pp. 380-404.

POLANYI, K. (2012 [1944]). A grande transformação: as origens da nossa época. Rio de Janeiro, Elsevier.

RIBEIRO, D. (2006). O povo brasileiro: a formação e o sentido do Brasil. São Paulo, Companhia das Letras.

SIMMEL, G. (1973). "A metrópole e a vida mental”. In: VELHO, O. (org.). O fenômeno urbano. São Paulo, Zahar.

SIMONE, A. M. (2014). Jakarta: drawing the city near. Minneapolis, University of Minnesota Press.

STORPER, M. (2016). The neo-liberal city as idea and reality. Territory, Politics, Governance. v. 4, n .2, pp. 241-263.

TONUCCI FILHO, J. B. M. (2017). Comum urbano: a cidade além do público e do privado. Tese de Doutorado. Belo Horizonte, Universidade Federal de Minas Gerais.

WALL, D. (2014). The commons in history: culture, conflict, and ecology. Cambridge, Londres, MIT Press.

Texto recebido em 9/dez/2016

Texto aprovado em 5/abr/2017 